\title{
False Positive Computed Tomography Imaging for Coronavirus-2019
}

\author{
(D) Mehmet Hüsamettin Akküçük, (10 Mehmet Akif Karadaș, (1) Meltem Seviner, (1) Tayfun Anıl Demir, (1) Elif Kılıçlı Doğanay
}

Department of Emergency Medicine, Bașkent University Alanya Research and Practise Center, Antalya, Turkey

\begin{abstract}
A 79-year-old female patient presented to the emergency unit with cough and severe shortness of breath. Due to a bilateral multilobular ground glass density result from thoracic tomography, the patient was admitted to intensive care with the preliminary diagnosis of corona virus-2019 (COVID-19), and a continuous positive airway pressure was applied. A polymerase chain reaction (PCR) test was performed, and treatment with hydroxychloroquine and azithromycin was initiated. At the same time, the patient with an arterial blood pressure of 190/100 $\mathrm{mm} / \mathrm{hg}$ was administered with diuretic treatment to reduce lung congestion. The follow-up computed tomography of the patient showed rapid recovery, and ground glass appearances had completely resolved. The PCR was negative and the patient was diagnosed with acute lung edema. The treatment was prescribed, and the patient was discharged from the hospital. Thoracic tomography findings are useful in early period for COVID-19 diagnosis; however, it may show similar results as other diseases that cause respiratory failure and lead to misleading interpretations.
\end{abstract}

Keywords: COVID-19, Sars-CoV-2, computed tomography

\section{Introduction}

Diverse experiences are being shared by scientists in many countries on the diagnostic evaluations of the Coronavirus-2019 (COVID-19) pandemic, which emerged in the Wuhan province of China and affected the whole world. Although polymerase chain reaction $(\mathrm{PCR})$ is valuable in terms of diagnosis, it is also challenging to diagnose due to false negativity in early diagnosis. However, even though PCR is negative in thorax computed tomography (CT), there are many articles that report that peripheral and scattered bilateral consolidated areas are quite significant in early diagnosis of COVID-19 (1-3). We believe that CT will play an important role in the epidemic, which is also seen in our country, in the early diagnosis of patients, isolating the contacts and controlling the spread. While $91 \%$ of patients infected with COVID-19 apply with pneumonia, 3.4\% of them can be seen in the Acute Respiratory Distress Syndrome (ARDS) table and $1.1 \%$ in the shock table (4). In this sense, it was determined as the main target to start the drug protocol, which was established in the light of shared treatment regimens in the world, together with supportive treatment in the early period by making rapid evaluations in the diagnosis (5).

\section{Case Report}

A 79-year-old woman is brought to our emergency department by ambulance with shortness of breath and respiratory distress after a sudden cough. Vital signs of the patient who had aortic stenosis in her history and stated that her daughter was working as a nurse in COVID-19 pandemic hospital was noted as $\mathrm{SpO}_{2}$ : 81\% TA: $190 / 90$, fever: $36.3^{\circ} \mathrm{C}$. In her physical examination, she had a skin with sweaty skin, and Ronkus and rough rales in the lungs. The patient's blood gas was $\mathrm{Ph}: 7.1$ and $\mathrm{PO}_{2}: 62$ and $\mathrm{PCO}_{2}$ : 78.6 complete blood counts were $16000 / \mu \mathrm{L}$. Continuous Positive Airway Pressure (CPAP) was applied to the patient with severe respiratory distress by non-invasive mechanical ventilation. CRP, renal function tests and liver function tests parameters were within normal limits. Troponin I: 17,800 (0,000-16,000) was slightly above the upper value. When the thorax CT of the patient with sudden onset cough and respiratory distress was taken, hydroxychloroquine, influvir and azithromycin treatment was initiated by considering PCR, which is considered significant in terms of COVID-19 infection in both ac parenchyma, and widespread ground glass density and consolidated areas holding 
all segments on the left (Figure 1). In addition, diuretics were given to the patient, who was hypertensive, to reduce lung congestion. After 8 hours of intermittent CPAP support, blood gas and oxygenation improved, and the patient was followed up with nasal oxygen. Upon the clinical recovery of the patient who was taken into service on the $2^{\text {nd }}$ day, pro Bnp was sent to evaluate other differential diagnoses and control CT was planned. The patient's pro-bnp was very high $(6800 \mu / L)$, and there was no pathological finding other than minimal pleural effusion in the control CT taken on the $3^{\text {rd }}$ day (Figure 2). The patient, who had a negative COVID-19 PCR test, was treated and followed up by cardiology. On the $3^{\text {rd }}$ day, the patient recovered and was discharged with an outpatient treatment.

\section{Discussion}

There are many experiences in the literature about the characteristic features of pneumonia CT findings caused

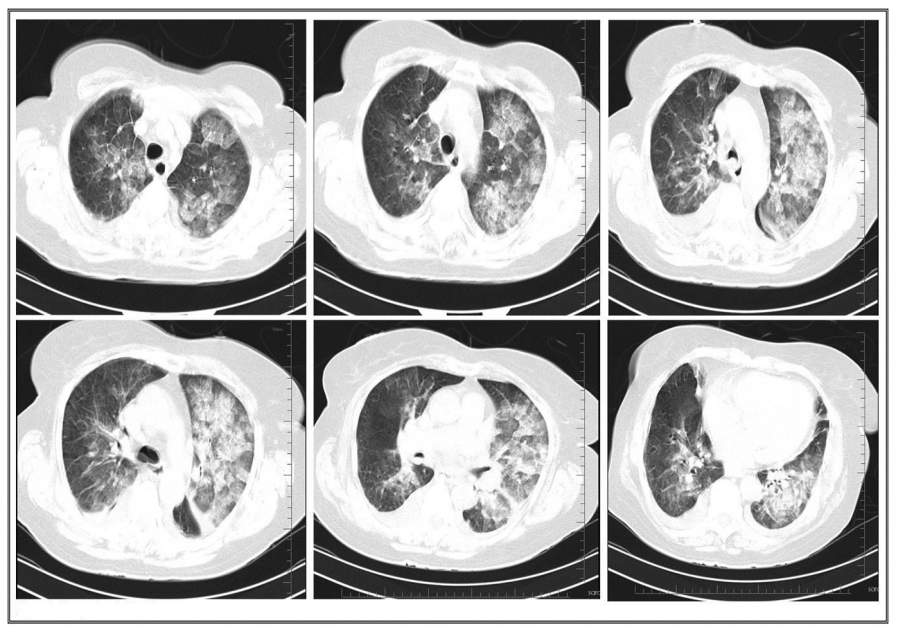

Figure 1. The patient's first CT scan

Ст: Computed tomography

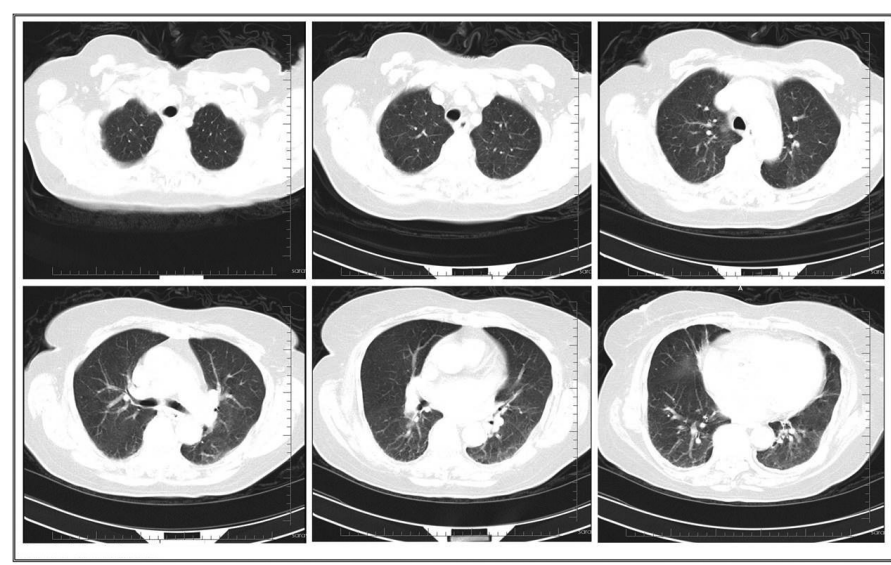

Figure 2. The patient's $3^{\text {rd }}$ day CT

CT: Computed tomography by COVID-19 $(1,3,6)$. In the light of this information, high concentration on pandemic may cause us to ignore other emergency diagnoses. In addition, given hydroxychrorocinin and azithromycin may cause morbidity and mortality due to cardiac side effects (7). Patients infected with COVID-19 may come on the shock table due to ARDS and myocardial involvement, and acute lung edema may also come with a similar clinic (1). In addition, physical examination and other differential examinations are less frequent with the concern of minimizing contact during the pandemic period. In this period, we wanted to remind that thorax CT image, which is not in the diagnostic algorithm but which we frequently use for differential diagnosis due to a pandemic, may be very similar and may be confused with COVID-19 pneumonia. Although $\mathrm{CT}$ is a powerful diagnostic method while performing COVID-19 diagnosis and treatment, we think it is useful to reexamine with PCR and clinic.

\section{Ethics}

Informed Consent: Informed consent was obtained.

Peer-review: Externally peer-reviewed.

\section{Authorship Contributions}

Concept: M.H.A., M.A.K., M.S., T.A.D., E.K.D., Design: M.H.A., M.A.K., M.S., T.A.D., E.K.D., Data Collection or Processing: M.H.A., M.A.K., M.S., T.A.D., E.K.D., Analysis or Interpretation: M.H.A., M.A.K., M.S., T.A.D., E.K.D., Literature Search: M.H.A., M.A.K., M.S., T.A.D., E.K.D., Writing: M.H.A., M.A.K., M.S., T.A.D., E.K.D.

Conflict of Interest: No conflict of interest was declared by the authors.

Financial Disclosure: The authors declared that this study received no financial support.

\section{References}

1. Dai WC, Zhang HW, Yu J, Xu HJ, Chen H, Luo SP, et al. CT Imaging and Differential Diagnosis of COVID-19. Can Assoc Radiol J. 2020;71:195-200.

2. Zhu, N, Zhang, D, Wang, W, Li X, Yang B, Song J, et al. A novel coronavirus from patients with pneumonia in China, 2019. N Engl J Med. 2020;383:72733.

3. Koo HJ, Lim S, Choe J, Choi SH, Sung H, Do KH. Radiographic and CT features of viral pneumonia. Radiographics. 2018;38:719-39.

4. Andersen KG, Rambaut A, Lipkin WI, Holmes EC, Garry H, Garry RF. The proximal origin of SARS-CoV-2. Nat Med 2020;26:450-2.

5. TC Sağlık Bakanlığı COVID-19 Bilgilendirme Sayfası. Available at: https:// covid19bilgi.saglik.gov.tr/tr/tedavi

6. Li B, Li X, Wang Y, Han Y, Wang Y, Wang C, et al. Diagnostic Value and Key Features of Computed Tomography in Coronavirus Disease 2019. Emerg Microbes Infect. 2020:1-14.

7. Chatre C, Roubille F, Vernhet H, Jorgensen C, Pers YM. Cardiac complications attributed to chloroquine and hydroxychloroquine: a systematic review of the literature. Drug Saf. 2018;41:919-31. 